\title{
A controlled, randomized trial of highly selective vagotomy versus selective vagotomy and pyloroplasty in the treatment of duodenal ulcer
}

\author{
O. KRONBORG ${ }^{1}$ AND P. MADSEN \\ From the Department of Surgical Gastroenterology A, Bispebjerg Hospital, Copenhagen, Denmark
}

SUMMARY The results of highly selective vagotomy without drainage and selective vagotomy with pyloroplasty for duodenal ulcer were compared in a randomized, controlled trial of a series of 100 patients. The frequency of dumping, diarrhoea, and epigastric fullness was significantly lower after highly selective $(6,6$, and $8 \%$ ) than after selective vagotomy $(30,20$, and $28 \%)$ one year after the operations. Recurrent and persisting duodenal ulcers appearing from one to four years after the operations were significantly more frequent after highly selective $(22 \%)$ than after selective vagotomy $(8 \%)$. No significant relationships were found between recurrent ulceration and gastric acid secretion measurements after the two operations. The Hollander response was early positive in $28 \%$ and late positive in $30 \%$ of the patients subjected to highly selective vagotomy, while the corresponding figures after selective vagotomy were 26 and $32 \%$.

The overall clinical results of the two operations were not different according to the classification of Visick. Excluding the patients with recurrence resulted in significantly better clinical results after highly selective vagotomy.

Recent studies (Humphrey and Wilkinson, 1972; Jensen and Amdrup, 1973) indicate that highly selective vagotomy without drainage in the treatment of duodenal ulcer promotes a low frequency of dumping and diarrhoea without a complementary rise in the risk of recurrent ulceration; indeed the frequency of recurrent ulceration is very low.

An evaluation of the merits of highly selective vagotomy requires a comparison with a conventional operative method in a controlled, randomized trial. As the results of such a trial has not yet been published, in November 1970 a controlled study was begun at Bispebjerg Hospital, Copenhagen. Highly selective vagotomy without drainage was compared with selective vagotomy and a Heineke-Miculicz pyloroplasty.

\section{Patients and Methods}

One hundred patients entered the trial from November 1970 to August 1974. The clinical re-

${ }^{1}$ Correspondence to Ole Kronborg, Kajerödvej 124, 3460 Birkeröd, Denmark

Received for publication 10 February 1975. sults are given at follow up studies one year after operation but recurrent ulcers appearing within four years are included. Ninety-six patients attended the one-year follow-up examination. Four could not be traced, but they were examined six months after the operation. All patients were asked a standard set of questions recorded on a questionnaire. Patients admitted for the trial were not more than 60 years old, had typical symptoms of duodenal ulcer, radiologically demonstrable duodenal ulcer, and no signs of pyloric stenosis. Those with concomitant disease in the gastrointestinal tract and/or evident mental disease were excluded. Only elective operations were considered. When the diagnosis was confirmed during operation, the cype of vagotomy was allocated at random using a double-blind, paired sample principle.

Thirty-six men and 14 women were allocated to highly selective vagotomy (HSV). The mean age was 45 and 48 years, respectively. Thirty-four men and 16 women were allocated to selective vagotomy and pyloroplasty (SV). The mean age was 51 and 43 years, respectively.

All patients were subjected to an insulin and an augmented histamine test before and about 10 days 


\begin{tabular}{|c|c|c|c|c|}
\hline & \multicolumn{2}{|c|}{$\begin{array}{l}\text { Highly Selective } \\
\text { Vagotomy }\end{array}$} & \multicolumn{2}{|c|}{$\begin{array}{l}\text { Selective } \\
\text { Vagotomy }\end{array}$} \\
\hline & Men & Women & Men & Women \\
\hline $\begin{array}{l}\text { No. } \\
\text { Preoperative PAO (m-equiv/h) } \\
\text { Postoperative PAO (m-equiv/h) } \\
\text { Postoperative maximum } \\
\text { acidity after insulin (MIA)- } \\
\text { mean spontaneous acidity } \\
\text { Postoperative PAO (I)-BAO }\end{array}$ & $\begin{array}{l}36 \\
48 \cdot 2 \\
19 \cdot 7 \\
\\
31 \\
4 \cdot 2\end{array}$ & $\begin{array}{l}14 \\
35 \cdot 6 \\
16 \cdot 1\end{array}$ & $\begin{array}{l}34 \\
47 \cdot 5 \\
20 \cdot 3\end{array}$ & $\begin{array}{l}16 \\
34 \cdot 6 \\
12 \cdot 3\end{array}$ \\
\hline $\begin{array}{l}\text { The Hollander response } \\
\text { Negative } \\
\text { Late positive } \\
\text { Early positive }(60 \mathrm{~min})\end{array}$ & $\begin{array}{l}12 \\
12 \\
12\end{array}$ & $\begin{array}{l}9 \\
3 \\
2\end{array}$ & $\begin{array}{r}14 \\
12 \\
8\end{array}$ & $\begin{array}{l}7 \\
4 \\
5\end{array}$ \\
\hline
\end{tabular}

Table I Mean values for gastric acid secretion measurements and Hollander responses

after the operation by a technique described previously (Kronborg and Madsen, 1972b). The acid secretion measurements are presented in table I. No differences were found between the groups, either before or after operation. Ninety-six of the 100 patients had a preoperative early positive Hollander response.

Serum gastrin measurements were performed before and after stimulation with insulin before and after operation in some of the patients (Kronborg, Stadil, Rehfeld, and Christiansen, 1973).

Highly selective and selective vagotomy were, with only a few modifications, performed as described by Amdrup and Jensen (1970). Atropine was not used before and during the operation. Gastric secretion was stimulated by tetragastrin (Leo) during the induction of anaesthesia. The dose was 10 microgram per $\mathrm{kg}$ body weight given subcutaneously. The border between antrum and corpus on the lesser curvature was localized by a $\mathrm{pH}$ tube (Rune, 1968). If the borderline could not be identified within 1 to $2 \mathrm{~cm}$ a gastrotomy was performed and the mucous membrane stained with Congo red. The mean distance from pylorus to the borderline in $47 \mathrm{HSV}$ patients was $8.6 \mathrm{~cm}$ (range 4-17).

The statistical evaluation comprised the unpaired t test, the chi square test, and the rank sum test.

\section{Results}

Operative mortality was nil. Severe postoperative complications were not seen. No patient died during the one-year follow up.

Dumping was more frequent after SV than after HSV ( $P<0.001)$, considering the sum of severe and slight symptoms and the severe symptoms alone (table II). Acid secretion measurements were not related to dumping after HSV but men with dump-

\begin{tabular}{lll}
\hline Dumping & \multicolumn{2}{l}{ Vagotomy } \\
\cline { 2 - 3 } & Highly Selective & Selective \\
\cline { 2 - 3 } & $\begin{array}{ll}\text { No. of } \\
\text { Patients }\end{array}$ & $\begin{array}{l}\text { No. of } \\
\text { Patients }\end{array}$ \\
\hline With need to lie down & $1(2 \%)$ & $10(20 \%)$ \\
Without need to lie down & $2(4 \%)$ & $5(10 \%)$ \\
\hline
\end{tabular}

Table II Dumping

\begin{tabular}{lll}
\hline & \multicolumn{1}{l}{ Vagotomy } \\
\cline { 2 - 3 } & Highly Selective & Selective \\
\cline { 2 - 2 } $\begin{array}{l}\text { No. of } \\
\text { Patients }\end{array}$ & $\begin{array}{l}\text { No. of } \\
\text { Patients }\end{array}$ \\
\hline $\begin{array}{lll}\text { Diarrhoea } \\
\text { Imperative need of defaecation }\end{array}$ & $\begin{array}{l}3(6 \%) \\
1(2 \%)\end{array}$ & $\begin{array}{r}10(20 \%) \\
6(12 \%)\end{array}$ \\
\hline
\end{tabular}

Table III Diarrhoea and imperative need of defaecation

ing after SV had a lower preoperative PAO than those without dumping $(P<0.02)$.

Diarrhoea was commoner after SV than after HSV $(P<0.05)$, while the imperative need of defaecation was insignificantly more frequent $(0.10$ $<$ P $<0.20$ ) (table III). Men with diarrhoea after SV had a lower acid response to insulin postoperatively than those without diarrhoea $(\mathrm{P}<$ 0.005).

Epigastric fullness was more frequent after SV $(P<0.01)$, while the difference in rate of occasional vomiting after HSV and SV was not significant (table IV). All patients with vomiting except one had epigastric fullness. The acid response to insulin in men with epigastric fullness after SV was significantly less than in those without $(P<0.02)$. Neither spontaneous nor activated acid secretion was related to occasional vomiting.

Recurrent or persisting duodenal ulcer was seen in 11 patients with HSV and in four with SV (table $V)$. This difference is significant $(P<0.05)$. Dyspepsia without demonstrable recurrent ulcer was seen in two patients after SV. Twelve of the 15 patients with recurrence were reoperated and a duodenal ulcer was found in all of them. No reoperation was performed in three patients with recurrence

\begin{tabular}{lll}
\hline & \multicolumn{2}{l}{ Vagotomy } \\
\cline { 2 - 3 } & Highly Selective & \multicolumn{1}{c}{ Selective } \\
& $\begin{array}{l}\text { No. of } \\
\text { Patients }\end{array}$ & $\begin{array}{l}\text { No. of } \\
\text { Patients }\end{array}$ \\
\hline Epigastric fullness & $4(8 \%)$ & $14(28 \%)$ \\
Vomiting & $2(4 \%)$ & $7(14 \%)$ \\
\hline
\end{tabular}

Table IV Epigastric fullness and vomiting 


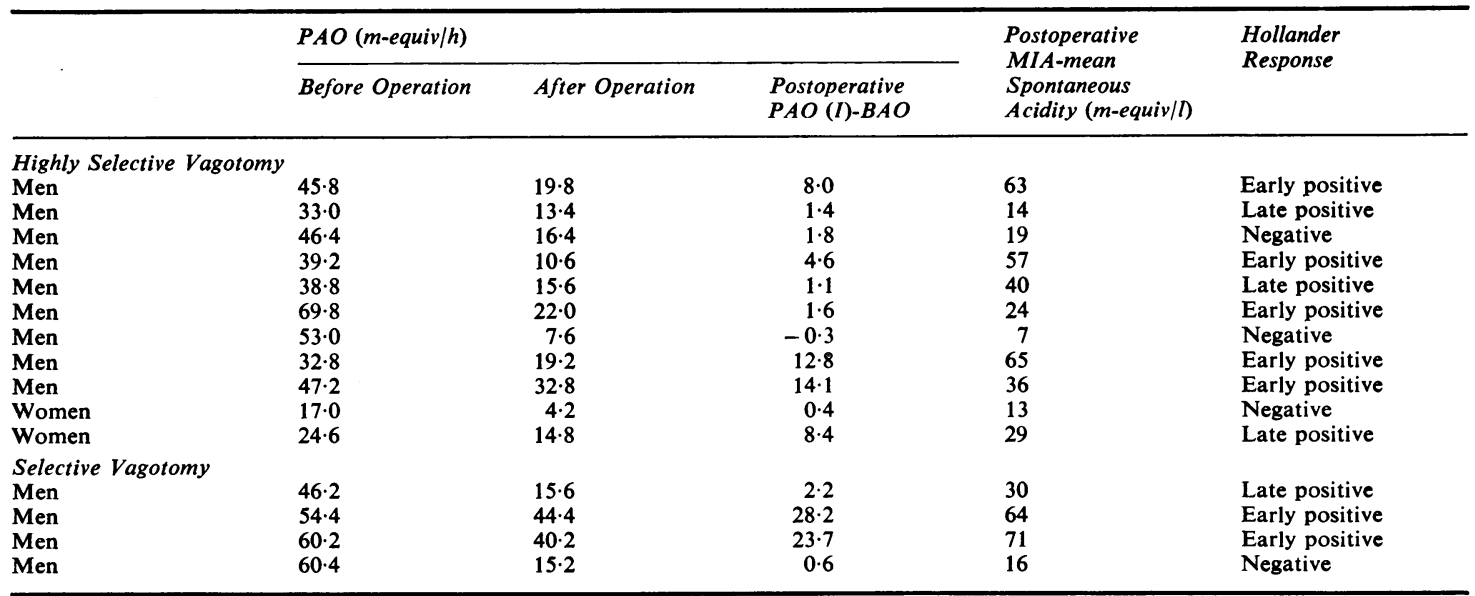

Table V Gastric acid secretion measurements and Hollander responses in patients with recurrent or persisting duodenal ulcer

after HSV. The ulcer healed in two, after they had ceased taking salicylic acid; a third ulcer healed spontaneously.

Gastric acid secretion measurements in patients with recurrent ulcer did not differ from those in patients without recurrence after HSV (table V). The four patients with recurrence after SV all had a high preoperative PAO, but the number was too small to allow a discrimination between recurrences and non-recurrences. Positive Hollander responses were not more frequent in patients with

\begin{tabular}{|c|c|c|}
\hline \multirow{3}{*}{$\begin{array}{l}\text { Visick } \\
\text { Grading }\end{array}$} & \multicolumn{2}{|l|}{ Vagotomy } \\
\hline & Highly Selective & Selective \\
\hline & $\begin{array}{l}\text { No. of } \\
\text { Patients }\end{array}$ & $\begin{array}{l}\text { No. of } \\
\text { Patients }\end{array}$ \\
\hline $\begin{array}{l}\text { I } \\
\text { II } \\
\text { III } \\
\text { IV }\end{array}$ & $\begin{array}{c}34(68 \%) \\
5(10 \%) \\
1(2 \%) \\
10(20 \%)\end{array}$ & $\begin{array}{c}20(40 \%) \\
14(28 \%) \\
12(24 \%) \\
4(8 \%)\end{array}$ \\
\hline
\end{tabular}

Table VI The overall clinical results of highly selective and selective vagotomy according toVisick grading

\begin{tabular}{|c|c|c|}
\hline \multirow[b]{3}{*}{$\begin{array}{l}\text { Visick } \\
\text { Grading }\end{array}$} & \multicolumn{2}{|l|}{ Vagotomy } \\
\hline & Highly Selective & Selective \\
\hline & $\begin{array}{l}\text { No. of } \\
\text { Patients }\end{array}$ & $\begin{array}{l}\text { No of } \\
\text { Patients }\end{array}$ \\
\hline $\begin{array}{l}\text { I } \\
\text { II } \\
\text { III }\end{array}$ & $\begin{array}{c}34(87 \%) \\
5(13 \%) \\
0(0 \%)\end{array}$ & $\begin{array}{l}20(44 \%) \\
14(30 \%) \\
12(26 \%)\end{array}$ \\
\hline
\end{tabular}

Table VII Clinical results of highly selective and selective vagotomy according to Visick excluding patients with recurrent ulceration recurrent ulcer than in those without, regardless of the operation performed. The distance from the pylorus to the antral borderline was not related to recurrence.

Serum gastrin concentrations were measured in 17 patients with HSV, including four with recurrent ulcer, and in 12 patients with SV, including two with recurrent ulcer. Fasting gastrin concentrations and gastrin responses to insulin were similar in patients with and without recurrence.

No differences were found between HSV and SV in overall clinical results (rank sum test) (table VI) Excluding the patients with recurrence from this evaluation, resulted in significantly better results after highly selective vagotomy $(P<0.0002)$ (table VII).

\section{Discussion}

The results of the trial confirm some of the findings in non-randomized studies; the incidence of dumping and diarrhoea is very low after HSV and lower than after SV. This is probably due to a normal or only slightly accelerated gastric emptying after HSV (Amdrup and Jensen, 1970; Madsen, Kronborg, and Feldt-Rasmussen, 1973). Epigastric fullness was also less frequent after HSV than after SV. The acid response to insulin was higher in SV patients without fullness than in those with, indicating a more intact vagal innervation and therefore better preservation of the receptive relaxation of the stomach in the former. The intact antral innervation after HSV may preserve the receptive relaxation in this part, resulting in no epigastric fullness. 
In a previous study (Kronborg and Madsen, 1972a) we did not find any relationship between preoperative PAO and dumping after truncal vagotomy and pyloroplasty, nor between gastric emptying time and preoperative PAO. However, the postoperative PAO(I) was slightly but significantly lower in patients with fast gastric emptying. The present lower acid response to insulin in patients with diarrhoea after SV than in those without diarrhoea suggests a positive relationship between completeness of vagotomy and diarrhoea, but this relationship is abolished by preserving the antral innervation. This implies that gastric emptying is dominated by the antrum, while denervation of the corpus and fundus only results in a fast gastric emptying rate and diarrhoea if the antrum is denervated and the pylorus destroyed.

The recurrence rate after HSV was surprisingly high. The reduction of PAO (histamine) was on average $59 \%$, a similar figure to those presented by Clarke, Allan, and Alexander-Williams (1972) and Johnston, Wilkinson, Humphrey, Smith, Goligher, Kragelund, and Amdrup (1973). The last mentioned authors found a very high proportion of negative Hollander responses one week after HSV (97 out of 100 responses) and none of their 280 patients had recurrent ulceration in spite of $51 \%$ of the responses (27 out of 53) being positive one year after HSV. The last figure is not different from our $58 \%$ ten days after HSV.

Recurrent ulceration has been reported in another, smaller series showing an incidence of positive Hollander responses in $28 \%$ of patients soon after HSV (Wastell, Colin, MacNaughton, and Gleeson, 1972).

No significant differences were detected in acid secretion measurements after HSV and SV, which could explain the difference in the recurrence rate. Also, no relationship was found between recurrence and gastrin, confirming the findings of Clark and Wyllie (1973).

Several surgeons performed the operations, but the recurrences could not be related to one or to a few surgeons. Subtracting the three recurring ulcers which healed, a recurrence rate of $16 \%$ after HSV remains. It seems that the low frequency of dumping and diarrhoea after HSV has to be paid for by a high recurrence rate. The equally good (or bad) results according to Visick demonstrate the complementary relationships between recurrence and postvagotomy symptoms in surgery for duodenal ulcer.

The study was supported by a grant from Statens lägevidenskabelige forskningsråd.

\section{References}

Amdrup, E., and Jensen, H. E. (1970). Selective vagotomy of the parietal cell mass preserving innervation of the undrained antrum. Gastroenterology, 59, 522-527.

Clark, C. G., and Wyllie, J. H. (1973). Gastrin and recurrent ulcer after vagotomy. Brit. J. Surg., 60, 319.

Clarke, R. J., Allan, R. N., and Alexander-Williams, J. (1972). The effect of retaining antral innervation on the reductions of gastric acid and pepsin secretion after vagotomy. Gut, 13, 894-899.

Humphrey, C. S., and Wilkinson, A. R. (1972). The value of preserving the pylorus in the surgery of duodenal ulcer. Brit. $J$. Surg., 59, 779-783.

Jensen, H. E., and Amdrup, E. (1973). Parietal cell vagotomy. 126 cases. Scand. J. Gastroent., 8, Suppl. 20, 11.

Johnston, D., Wilkinson, A. R., Humphrey, C. S., Smith, R. B., Goligher, J. C., Kragelund, E., and Amdrup, E. (1973). Serial studies of gastric secretion in patients after highly selective (parietal cell) vagotomy without a drainage procedure for duodenal ulcer. Gastroenterology, 64, 1-21.

Kronborg, O., and Madsen, P. (1972a). Gastric emptying rate and acid secretion after truncal vagotomy and pyloroplasty for duodenal ulceration. Scand. J. Gastroent., 7, 515-518.

Kronborg, O., and Madsen, P. (1972b). A comparison of gastric acid secretions after highly selective vagotomy without drainage and selective vagotomy with a pyloroplasty. Scand. J. Gastroent., 7, 615-621.

Kronborg, O., Stadil, F., Rehfeld, J., and Christiansen, P. M. (1973). Relationship between serum gastrin concentrations and gastric acid secretion in duodenal ulcer patients before and after selective and highly selective vagotomy. Scand. J. Gastroent. $8,491-496$.

Madsen, P., Kronborg, O., and Feldt-Rasmussen, K. (1973). The gastric emptying and small intestinal transit after highly selective vagotomy without drainage and selective vagotomy with pyloroplasty. Scand. J. Gastroent., 8, 541-543.

Rune, S. J. (1968). An electrode for $\mathrm{pH}$ measurement in the gastrointestinal tract. Scand. J. Gastroent., 3, 91-94.

Wastell, C., Colin, J. F., MacNaughton, J. I., and Gleeson, J. (1972). Selective proximal vagotomy with and without pyloroplasty. Brit. med. J., 1, 28-30. 